\title{
Risk factors for persistent otitis media with effusion in children: a case-control study
}

\author{
Ju Yeon Lee ${ }^{1}$, Se-Hyung Kim², Chan II Song ${ }^{2}$, Young Ree $\mathrm{Kim}^{3}$, Yoon-Joo Kim ${ }^{4}$, Jae Hong Choi ${ }^{4}$ \\ ${ }^{I}$ Department of Pediatrics, Jeju National University Hospital; Departments of ${ }^{2}$ Otorhinolaryngology, \\ ${ }^{3}$ Laboratory Medicine, ${ }^{4}$ Pediatrics, Jeju National University School of Medicine, Jeju, Korea
}

Background: Otitis media with effusion (OME) is defined as middle ear effusion without acute signs of infection. OME usually resolves spontaneously; however, persistent OME may require the insertion of a ventilation tube. This study investigated risk factors for persistent OME in children who undergo ventilation tube insertion. Methods: Children who were admitted to undergo ventilation tube insertion at Jeju National University Hospital between August 2015 and July 2016 were enrolled as the case group. Healthy children without persistent OME from August 2016 to July 2017 were enrolled as the control group. Baseline characteristics and predisposing factor data were collected using an interview questionnaire. Middle ear fluids were collected from the case group.

Results: A total of 31 patients underwent ventilation tube insertion. The mean age of the case group was 4.53 years, with a male-to-female ratio of $21: 10$. Twenty-nine $(93.5 \%)$ children attended a daycare center, and $21(67.7 \%)$ had experience with bottle feeding. Fifteen $(48.4 \%)$ children in the case group and $3(9.7 \%)$ in the control group first attended a daycare center at $<1$ year of age (odds ratio $=9.96 ; 95 \%$ confidence interval=2.44-39.70; $p=0.001$ ). No bacteria were found in middle ear fluid collected from the 31 operated children. Nasopharyngeal bacterial colonization was found in $13(41.9 \%)$ and $17(54.8 \%)$ children in the case and control groups, respectively.

Conclusion: Earlier attendance at a daycare center was the only predisposing factor for ventilation tube insertion in our study. The aseptic nature of middle ear fluids found in children with OME highlights the efficacy of antimicrobial use.

Keywords: Otitis media with effusion; Middle ear ventilation; Risk factors

\section{INTRODUCTION}

Otitis media with effusion (OME) is characterized by a nonpurulent effusion from the middle ear without symptoms such as otalgia or fever. OME is believed to follow an episode

Received: April 3, 2018, Revised: May 10, 2018

Accepted: May 31, 2018

Corresponding Author: Jae Hong Choi, Department of Pediatrics, Jeju National University School of Medicine, Aran-13gil, Jeju 63241, Korea

Tel: +82-64-717-1476, Fax: +82-64-717-1079

E-mail: jhchoi@jejunu.ac.kr of acute otitis media or abnormal Eustachian tube function. Individuals with OME usually exhibit no specific symptoms; the disease is self-limited within approximately 3 months without specific treatment [1]; however, it does recur in $30-40 \%$ of cases [2].

Some birth cohorts have reported that $>90 \%$ children experience at least one episode of OME before 4 years of age $[2,3]$. OME is the most common cause of acquired hearing impairment in children; permanent hearing loss related to otitis media has a prevalence of 2-35 per 10,000. Although symptoms are not severe, the highest incidence of OME occurs during a highly important period of language skill de-

Copyright $($ C) 2018 Yeungnam University College of Medicine

This is an Open Access article distributed under the terms of the Creative Commons Attribution Non-Commercial License (http://creativecommons.org/licenses/by-nc/4.0/) which permits unrestricted non-commercial use, distribution, and reproduction in any medium, provided the original work is properly cited. 
velopment. Thereafter, periodic hearing tests are essential to preserving hearing ability in OME patients [4].

The ultimate treatment goal for $\mathrm{OME}$ is to mitigate hearing loss. American guidelines recommend that physicians manage children with $\mathrm{OME}$ who are not at risk with watchful waiting for 3 months from the date of effusion onset without antimicrobial treatment $[4,5]$. However, the guidelines also recommend that clinicians offer ventilation tube insertion to children with documented hearing difficulties, structural abnormalities of the tympanic membrane or middle ear, increased risk for speech and/or language difficulties, and/or reduced quality of life in cases of OME lasting $\geq 3$ months [5].

Predisposing factors for persistent OME that require ventilation tube insertion include: attendance at a day care center, familial history of otitis media, low socio-economic status, tobacco smoke exposure and adenoid hypertrophy [6,7]. Allergic tendency or biofilm formation of nasal colonizing bacteria is suspected to contribute to the pathogenesis of persistent OME [8-10]. Recurrent otitis media is known to be another risk factor for persistent OME. Although the pathogenesis of recurrent otitis media is multifactorial, the invasion of nasopharyngeal colonizing bacteria is believed to be related $[11,12]$. The most frequent pathogens colonizing the nasopharynx include Streptococcus pneumoniae, Haemophilus influenzae, and Moraxella catarrhalis.

In Korea, the clinical guidelines for pediatric otitis media has been updated [13]. This domestic guideline recommends the appropriate use of antimicrobials, an indication for ventilation tube insertion, and the importance of hearing tests during treatment for OME, which were not different from other guidelines $[4,13]$. However, long-term antimicrobial use ( $>3$ months) for the treatment of OME was usually found in the clinical field.

A previous domestic study investigating OME reported risk factors for children undergoing recurrent ventilation tube insertion or ventilation tube insertion for children with craniofacial abnormalities [14]. We investigated the risk factors for persistent OME in children according to need for middle ear ventilation. Our aim was to determine the relationship between the colonization of bacteria in the nasopharynx and middle ear effusion.

\section{MATERIALS AND METHODS}

\section{Study subjects and design}

The present investigation was a prospective case-control study. Children $<12$ years of age, who were admitted for ventilation tube insertion at Jeju National University Hospital (JNUH) between August 2015 and July 2016, were enrolled as the case group. All participants were enrolled when they were definitively diagnosed with OME by two otolaryngologists. The children were scheduled to undergo middle ear ventilation for persistent OME 3 months after diagnosis, despite previous antimicrobial use. Patients with immunodeficiency disorders or craniofacial abnormalities, such as cleft palate and/or cleft lip, were excluded. However, patients who previously underwent ventilation tube insertion were included.

A group of age- and sex-matched subjects representing the controls was chosen from a group of healthy children without persistent OME, who visited the JNUH between August 2016 and July 2017. Apart from no history of persistent OME, subjects with recurrent acute otitis media were excluded. The present study was approved by the Institutional Review Board of Jeju National University Hospital (IRB No. 2015-05-006). Informed written consent was obtained from all participants before enrollment.

\section{Data and specimen collection}

Baseline characteristics and predisposing factors for the case and control groups were collected using a questionnaire interview. Investigated factors included: age, sex, familial member, pattern of daycare center attendance, recent history of antimicrobial use, history of breastfeedin, exposure to tobacco smoke in the house and vaccination history. Daycare center attendance was defined as attendance at a daycare center for at least 6 months, or younger subjects who attended a daycare center when enrolled in the study. Breastfeeding was defined in children who were breastfed for at least 2 months, and was distinguished from bottle feeding. History of pneumococcal conjugate and $H$ influenzae type b vaccination was also examined.

Microbiological investigations of middle ear effusions and colonization of the nasopharynx were performed. After aseptic myringotomy during surgery for ventilation tube insertion, a middle ear effusion sample was obtained using a sterile 
calcium alginate swab. If the middle ear effusion was glue-like in consistency, $0.5 \mathrm{~mL}$ of normal saline was instilled into the middle ear and the specimen was drawn using the same method. Nasopharyngeal aspirates were obtained from both the case and control groups. The same sterile calcium alginate swab was passed through a single anterior nostril to reach the nasopharynx and was rotated. All specimens were plated on trypticase soy agar plates containing 5\% sheep blood and chocolate agar plates, and were incubated overnight at $37^{\circ} \mathrm{C}$ in $5 \% \mathrm{CO}_{2}$. The identification of bacteria was limited to $S$. pneumoniae, $H$. influenzae, and $M$. catarrhalis, which are known to be the three major pathogens for otitis media. The identification method used was a routine biochemical test using the Vitek II system (bioMerieux Vitek Inc., Durham, NC, USA).

\section{Statistical analysis}

Statistical analysis was performed using $\mathrm{R}$ software version 3.4.3 (R Foundation for Statistical Computing, Vienna, Austria). The relationship between the investigated risk factors and middle ear ventilation tube insertion was analyzed using the chi-square test. Multivariate logistic regression analysis was performed, and the data are expressed as odds ratio (OR) and $95 \%$ confidence interval (CI). All tests were two tailed, and $p<0.05$ was considered to be statistically significant.

\section{RESULTS}

A total of 31 patients (21 male, 10 female) underwent ventilation tube insertion. The mean age of the case group was 4.53 years (median age, 4.20 years [range, $0.95-12.00$ years]); the mean age of the control group was 4.06 years (median age, 3.88 years [range, $0.74-12.22$ years]). In the case group, 26 patients underwent bilateral ventilation tube insertion, and 11 underwent unilateral insertion. There were no complications after the operation. Before the operation, hearing tests, such as tympanometry or pure tone audiometry, were performed in $20(64.5 \%)$ patients. All of them had hearing loss; more specifically, 18 (90\%) had 20-40 dB hearing loss, and $2 \mathrm{had}<20 \mathrm{~dB}$ hearing loss. We determined ventilation tube insertion after counselling in 11 patients who did not undergo a hearing test because the parents complained of middle ear effusion $>3$ months.
In the case group, 29 (93.5\%) children attended a daycare center, which was more than in the control group $(n=23)$; this difference was not statistically significant $(\mathrm{OR}=5.04$; 95\% CI=0.98-26.09; $p=0.084$ ) (Table 1). However, the number of subjects $<1$ year of age who attended a daycare center was $15(48.4 \%)$ in the case group, which was significantly more than the number of children in the control group $(n=3$ [48.4\%]); this difference was statistically significant $(\mathrm{OR}=$ 9.96; 95\% CI=2.44-39.70; $p=0.001$ ) (Fig. 1). There were more breastfed children in the control group $(n=22)$ than in the case group $(\mathrm{n}=19)(p=0.592)$, and more bottle-fed children in the case group $(\mathrm{n}=21)$ than in the control group $(\mathrm{n}=$ 18) $(p=0.599)$. However, these feeding habits had no statistically significant influence on ventilation tube insertion for OME (Table 1). Exposure to household tobacco smoke appeared to have no significant effect on persistent OME. Regardless of whether subjects had siblings, there were no differences in the prevalence of persistent OME. In the case group, there were no siblings who underwent ventilation tube insertion.

Eighteen (58.1\%) children in the case group and 16 (51.6\%) in the control group were taking antibiotics for persistent OME. Contrary to expectations, no bacteria were isolated from middle ear effusions collected from those who underwent ventilation tube insertion. The positive nasopharyngeal carriage rate was $41.9 \%(13 / 31)$ in the case group: $S$. pneumoniae $(\mathrm{n}=6) ; H$. influenzae $(\mathrm{n}=2)$; and $M$. catarrhalis $(\mathrm{n}=6)$. In the control group, the nasopharyngeal carriage rate was 54.8\% (17/31): S. pneumoniae $(\mathrm{n}=6) ; H$. influenzae $(\mathrm{n}=7)$; and $M$. catarrhalis $(\mathrm{n}=5)$ (Table 2$)$.

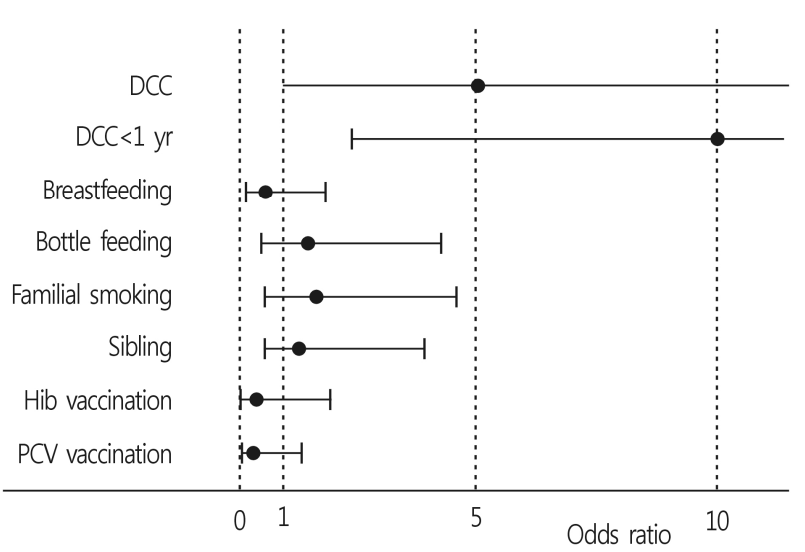

Fig. 1. Odds ratio of patient characteristics who underwent ventilation tube insertion. DCC, daycare center; Hib, Haemophilus influenzae type b; PCV, pneumococcal conjugate vaccine. 
Table 1. General characteristics of otitis media in the case and control groups

\begin{tabular}{|c|c|c|c|c|}
\hline Variable & $\begin{array}{c}\text { Case group }(\mathrm{n}=31) \\
\text { Number }(\%)\end{array}$ & $\begin{array}{c}\text { Control group }(n=31) \\
\text { Number }(\%)\end{array}$ & $\mathrm{OR}^{\mathrm{a})}(95 \% \mathrm{CI})$ & $p$-value \\
\hline Gender (male:female) & $21: 10$ & $21: 10$ & & \\
\hline Mean age (yr) (range) & $4.53(0.95-12.00)$ & $4.06(0.74-12.22)$ & & \\
\hline Daycare center & $29(93.5)$ & $23(74.2)$ & $5.04(0.98-26.09)$ & 0.084 \\
\hline$<1 \mathrm{yr}^{\mathrm{b})}$ & $15(48.4)$ & $3(9.7)$ & $9.96(2.44-39.70)$ & 0.001 \\
\hline Breast feeding & $19(61.3)$ & $22(71.0)$ & $0.64(0.22-1.87)$ & 0.592 \\
\hline Bottle feeding & $21(67.7)$ & $18(58.1)$ & $1.51(0.53-4.27)$ & 0.599 \\
\hline Familial smoking & $18(58.1)$ & $14(45.2)$ & $1.68(0.62-4.59)$ & 0.445 \\
\hline Sibling & $22(71.0)$ & $20(64.5)$ & $1.34(0.61-3.91)$ & 0.785 \\
\hline Hib vaccination & $25(80.6)$ & $28(90.3)$ & $0.45(0.10-1.97)$ & 0.471 \\
\hline PCV vaccination & $20(64.5)$ & $25(80.6)$ & $0.43(0.13-1.38)$ & 0.254 \\
\hline
\end{tabular}

OR, odds ratio; CI, confidence interval; Hib, Haemophilus influenzae type b; PCV, pneumococcal conjugate vaccine.

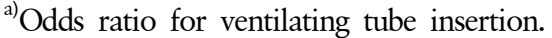

${ }^{b}$ First attending age at daycare center was lesser than 1 year old.

Table 2. Microbiological status of otitis media in the case and control groups

\begin{tabular}{lcr}
\hline \multicolumn{1}{c}{ Microbiologic status } & Case & \multicolumn{1}{c}{ Control } \\
\hline Middle ear fluid & $0(0.0)$ & $\mathrm{NA}^{\mathrm{a})}$ \\
Nasopharyngeal aspirate & $13(41.9)$ & $17(54.8)$ \\
S. pneumoniae & $6(19.4)$ & $6(19.4)$ \\
H. influenzae & $2(6.5)$ & $7(22.6)$ \\
M. catarrhalis & $6(19.4)$ & $5(16.1)$ \\
Previous antibiotics & $18(58.1)$ & $16(51.6)$ \\
\hline
\end{tabular}

Values are presented as number (\%).

${ }^{a)}$ Not applicable, b) antibiotics usage within 2 months before enrolling the study.

\section{DISCUSSION}

This investigation was a prospective study aimed at determining risk factors for ventilation tube insertion for persistent OME that did not spontaneously improve in children. Another goal of this study was to identify the relationship between nasopharyngeal colonizing bacteria and persistent middle ear effusion. Two otolaryngologists with experience in ventilation tube insertion in the middle ear were involved in this study. Indications for ventilation tube insertion were significant hearing loss due to persistent middle ear effusion, and persistent OME $>3$ months, which was refractory to spontaneous improvement despite of the use of antibiotics.

OME may occur after an upper respiratory tract infection due to poor Eustachian tube function or as a result of recurrent acute otitis media. A major risk factor for developing $\mathrm{OME}$ is age because of its direct correlation with the angula- tion of the Eustachian tube. Other factors reported to increase the risk for developing OME include daycare center attendance, exposure to tobacco smoke, low socio-economic status, shorter duration of breastfeeding, adenoid hypertrophy, and recurrent otitis media $[6,7,15,16]$.

In our study, children $<1$ year of age, who attended a daycare center, was the only statistically significant risk factor (Fig 1). Usually, younger children had more respiratory tract infections than adults because of their immature immune system. In addition, daycare center attendance enhances close contact with other children in confined spaces. In the present study, however, daycare attendance regardless of age had no clinically significant association with persistent OME. We speculate that the difference is the diluted result because of high attendance rates at daycare centers in both the case and control groups (52/62 [83.9\%]). We did not use data for recurrent otitis media as a risk factor for persistent OME. The recall ability of the patients' parents regarding the number of episodes or treatment of otitis media was uncertain. Attendance at a daycare center, however, was easy to recall, and this factor was believed to be related to recurrent otitis media. We used this particular questionnaire for our investigation based on previous studies $[17,18]$.

Exposure to household tobacco smoke and breastfeeding were not significant factors for persistent OME. We had no method to quantitatively evaluate the level of smoke exposure or breastfeeding. There was no relationship between bottle feeding and persistent OME. We speculate that this can be explained by the fact that most of our participants com- 
bined breast and bottle feeding.

Experts have recommended the use of pneumatic otoscopy or tympanometry to assess OME with hearing loss [4]. Furthermore, the first-line treatment choice to manage persistent OME in individuals not at risk is watchful waiting for 3 months from the date of effusion onset. This recommendation was applied to children with hearing loss $<20 \mathrm{~dB}$. Ventilation tube insertion is the definitive treatment for removing middle ear effusions and an effective method to prevent conductive hearing loss caused by middle ear effusion. Operative methods, such as ventilation tube insertion, are especially recommended when structural damage to the tympanic membrane, tympanosclerosis, cholesteatoma, symptoms of otalgia or vertigo, and hearing loss $>40 \mathrm{~dB}$, are found $[4,19]$.

Previous studies have reported that bacterial prevalence in middle ear effusions is $20-50 \%$, although the population was diagnosed as acute otitis media or OME [20-23]. We assumed that some bacteria could be expected to be found in middle ear effusions, and the pathogen could have a relationship with nasopharyngeal colonizing bacteria. However, no bacteria were isolated from any of the 31 middle ear effusion samples collected. This may be explained by the indication for ventilation tube insertion that was applied to the study population, which was different from other studies. Regardless of antimicrobial use in the recent 2 months, the sterile nature of middle ear effusions support no need for antibiotics to treat persistent OME. The American clinical guidelines also made strong recommendations against using systemic antibiotics for treatment OME in children [4].

Recently, molecular genetic techniques, such as polymerase chain reaction (PCR), have replaced conventional culture methods. Using these recently developed techniques, detection rates of causative pathogens have increased. This methodology has been applied to middle ear fluid specimens [24,25]. However, we could not perform a PCR assay due to a storage problem. In addition, considering the over-detection of inactive bacteria in PCR assays, we focused on living bacteria isolated using conventional culture methods.

The contribution of nasopharyngeal colonizing bacteria to otitis media has been established, and the bacterial pathogens had been studied [26,27]. In our study, there was no difference in antimicrobial use during a recent 2-month period between the case and control groups. However, nasopharyngeal colonization rates in the control group (54.8\%) were greater than those in the case group (41.9\%). This result suggests that other factors, in addition to nasopharyngeal colonizing bacteria, contribute to persistent OME. We cannot draw definitive conclusions because some patients in the control group visited our hospital complaining of respiratory symptoms.

This study had some limitations, the first of which were the relatively small sample size and its single-center design. Other predisposing factors, such as adenoid hypertrophy and allergic disorders, could not be investigated. If patients who spontaneously improved after the diagnosis of OME were investigated, risk factors for ventilation tube insertion could be more defined. Despite these limitations, this study should prompt clinicians to prospectively investigate risk factors for ventilation tube insertion in patients with OME disease only. Additionally, during the study period, we applied strict indications for ventilation tube insertion while considering the guidelines. We were able to confirm the principle of test hearing loss watching for spontaneous improvement. The sterile middle ear fluid found in children with OME children support the efficacy of antimicrobial use. Earlier attendance at a daycare center was the only statistically significant risk factor and, therefore, should prompt careful consideration before a decision is made to send a child to a daycare center. Future studies investigating OME should further examine the relationship between ventilation tube insertion and antimicrobial use. Furthermore, we believe that molecular-based methods investigating middle ear effusion and nasopharyngeal aspirates are promising research areas to pursue.

\section{ACKNOWLEDGEMENT}

This work was supported by a research grant from Jeju National University Hospital in 2015.

\section{CONFLICT OF INTEREST}

No potential conflict of interest relevant to this article was reported.

\section{ORCID}

Ju Yeon Lee, https://orcid.org/0000-0003-4172-2766

Se-Hyung Kim, https://orcid.org/0000-0002-1694-9435 
Chan Il Song, https://orcid.org/0000-0002-2705-4100

Yoon-Joo Kim, https://orcid.org/0000-0002-2832-036X

Jae Hong Choi, https://orcid.org/0000-0003-3284-9407

\section{REFERENCES}

1. Teele DW, Klein JO, Rosner BA. Epidemiology of otitis media in children. Ann Otol Rhinol Laryngol Suppl 1980;89:5-6.

2. Williamson IG, Dunleavey J, Bain J, Robinson D. The natural history of otitis media with effusion--a three-year study of the incidence and prevalence of abnormal tympanograms in four South West Hampshire infant and first schools. J Laryngol Otol 1994;108:930-4.

3. Tos M. Epidemiology and natural history of secretory otitis. Am J Otol 1984;5:459-62.

4. Rosenfeld RM, Shin JJ, Schwartz SR, Coggins R, Gagnon L, Hackell JM, et al. Clinical practice guideline: otitis media with effusion (update). Otolaryngol Head Neck Surg 2016; 154(1 Suppl):S1-41.

5. Rosenfeld RM, Schwartz SR, Pynnonen MA, Tunkel DE, Hussey HM, Fichera JS, et al. Clinical practice guideline: Tympanostomy tubes in children. Otolaryngol Head Neck Surg 2013;149(1 Suppl):S1-35.

6. Williamson I. Otitis media with effusion in children. BMJ Clin Evid 2011;2011. pii: 0502.

7. Owen MJ, Baldwin CD, Swank PR, Pannu AK, Johnson DL, Howie VM. Relation of infant feeding practices, cigarette smoke exposure, and group child care to the onset and duration of otitis media with effusion in the first two years of life. J Pediatr 1993;123:702-11.

8. Alles R, Parikh A, Hawk L, Darby Y, Romero JN, Scadding G. The prevalence of atopic disorders in children with chronic otitis media with effusion. Pediatr Allergy Immunol 2001;12: 102-6.

9. Gok U, Bulut Y, Keles E, Yalcin S, Doymaz MZ. Bacteriological and PCR analysis of clinical material aspirated from otitis media with effusions. Int J Pediatr Otorhinolaryngol 2001; 60:49-54.

10. Kreiner-Møller E, Chawes BL, Caye-Thomasen P, Bønnelykke $\mathrm{K}$, Bisgaard $\mathrm{H}$. Allergic rhinitis is associated with otitis media with effusion: a birth cohort study. Clin Exp Allergy 2012;42: 1615-20.

11. Faden H, Duffy L, Wasielewski R, Wolf J, Krystofik D, Tung Y. Relationship between nasopharyngeal colonization and the development of otitis media in children. J Infect Dis 1997; 175:1440-5.

12. García-Rodríguez JA, Fresnadillo Martínez MJ. Dynamics of nasopharyngeal colonization by potential respiratory pathogens. J Antimicrob Chemother 2002;50(Suppl S2):59-73.

13. Korean Otologic Society. Korean clinical practive guideline: otitis media in children 2014 [Internet]. Seoul: Korean Medical Guideline Information Center; 2014 [cited 2018 April 3]. http://www.otologicalsociety.or.kr

14. Ahn JH, Yoon TH, Pae KH, Kim TS, Chung JW, Lee KS.
Clinical manifestations and risk factors of children receiving triple ventilating tube insertions for treatment of recurrent otitis media with effusion. Pediatrics 2006;117:e1119-23.

15. Pestalozza G, Romagnoli M, Tessitore E. Incidence and risk factors of acute otitis media and otitis media with effusion in children of different age groups. Adv Otorhinolaryngol 1988;40:47-56.

16. Casselbrant ML, Mandel EM, Doyle WJ. Information on comorbidities collected by history is useful for assigning Otitis Media risk to children. Int J Pediatr Otorhinolaryngol 2016; 85:136-40.

17. Kim EJ, Kwon YR, Song KH, Jang WN, Lee J, Chang JK, et al. A study on risk factors of recurrent otitis media. Korean J Pediatr Infect Dis 2010;17:91-100. Korean.

18. Rovers MM, Zielhuis GA, Ingels K, van der Wilt GJ. Day-care and otitis media in young children: a critical overview. Eur J Pediatr 1999;158:1-6.

19. Khanna R, Lakhanpaul M, Bull PD; Guideline Development Group. Surgical management of otitis media with effusion in children: summary of NICE guidance. Clin Otolaryngol 2008; 33:600-5.

20. Poetker DM, Lindstrom DR, Edmiston CE, Krepel CJ, Link TR, Kerschner JE. Microbiology of middle ear effusions from 292 patients undergoing tympanostomy tube placement for middle ear disease. Int J Pediatr Otorhinolaryngol 2005;69: 799-804.

21. Kim SH, Jeon EJ, Hong SM, Bae CH, Lee HY, Park MK, et al. Bacterial species and antibiotic sensitivity in korean patients diagnosed with acute otitis media and otitis media with effusion. J Korean Med Sci 2017;32:672-8.

22. Holder RC, Kirse DJ, Evans AK, Peters TR, Poehling KA, Swords WE, et al. One third of middle ear effusions from children undergoing tympanostomy tube placement had multiple bacterial pathogens. BMC Pediatr 2012;12:87.

23. Ngo CC, Massa HM, Thornton RB, Cripps AW. Predominant bacteria detected from the middle ear fluid of children experiencing otitis media: a systematic review. PLoS One 2016;11: e0150949.

24. Farajzadah Sheikh A, Saki N, Roointan M, Ranjbar R, Yadyad MJ, Kaydani A, et al. Identification of Alloiococcus otitidis, Streptococcus pneumoniae, Moraxella catarrhalis and Haemophilus influenzae in children with otitis media with effusion. Jundishapur J Microbiol 2015;8:e17985.

25. Jervis-Bardy J, Carney AS, Duguid R, Leach AJ. Microbiology of otitis media in Indigenous Australian children: review. J Laryngol Otol 2017;131(S2):S2-11.

26. Mills N, Best EJ, Murdoch D, Souter M, Neeff M, Anderson $\mathrm{T}$, et al. What is behind the ear drum? The microbiology of otitis media and the nasopharyngeal flora in children in the era of pneumococcal vaccination. J Paediatr Child Health 2015;51:300-6.

27. Nourizadeh N, Ghazvini K, Gharavi V, Nourizadeh N, Movahed R. Evaluation of nasopharyngeal microbial flora and antibiogram and its relation to otitis media with effusion. Eur Arch Otorhinolaryngol 2016;273:859-63. 